\title{
Clinical long-term outcome after implantation of titanium nitride-oxide coated stents compared with paclitaxel- or sirolimus-eluting stents: propensity-score matched analysis
}

\author{
Andreas Limacher ${ }^{1}, \mathrm{PhD}$; Lorenz Räber ${ }^{2}, \mathrm{MD}$; Eva Laube², MD; Annette Lauterburg², MD; \\ Sylvan Lötscher², MD; Nina Hess², MD; Aris Moschovitis², MD; Samuel H. Baldinger², MD; \\ Peter Wenaweser ${ }^{2}$, MD; Bernhard Meier ${ }^{2}$, MD; Otto M. Hess² ${ }^{2}$ MD; Peter Jüni ${ }^{1,3 *}$, MD

\section{CTU Bern, Bern University Hospital, Switzerland; 2. Swiss Cardiovascular Center Bern, Bern University Hospital, Switzerland; 3. Institute of Social and Preventive Medicine, University of Bern, Switzerland}

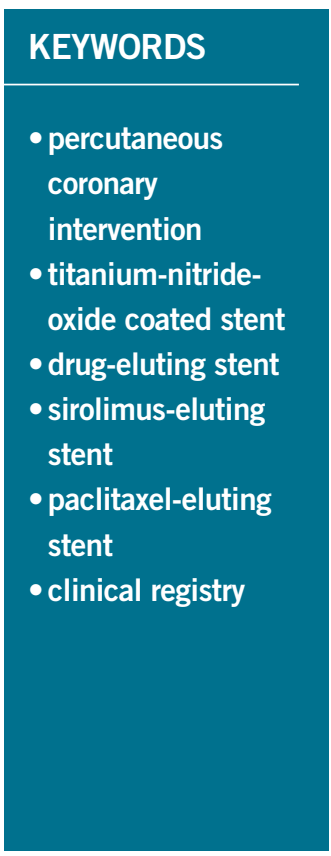

\begin{abstract}
Aims: We performed a propensity score matched analysis to explore whether TiNOX stents are superior to paclitaxel-(PES) and sirolimus-eluting stents (SES) in routine clinical practice.

Methods and results: A total of 1,607 patients undergoing implantation of SES, PES or TiNOX stents were prospectively entered into a stent registry and followed up for three years. Using propensity score matching, we compared clinical outcome among 319 pairs of patients treated with TiNOX stents or SES and 337 pairs of patients treated with TiNOX stents or PES. The primary outcome MACE, a composite of death, myocardial infarction, and target vessel revascularisation occurred in 20\% of patients with TiNOX stents, $19 \%$ of patients with SES and 23\% of patients with PES at 3-years. The hazard ratio was 1.00 comparing TiNOX stents with SES (95\% CI 0.69-1.45, p=1.00), and 0.95 comparing TiNOX stents with PES (95\% CI 0.66-1.36, $\mathrm{p}=0.78)$.
\end{abstract}

Conclusions: We did not find evidence to suggest superiority of TiNOX stents over SES or PES. In view of similar clinical outcomes, but with the reduced duration of dual antiplatelet therapy used with the TiNOX stent, we suggest that TiNOX stents may be an alternative to drug-eluting stents in patients unsuitable for long-term dual antiplatelet therapy.

\footnotetext{
*Corresponding author: Institute of Social and Preventive Medicine, University of Bern, Finkenhubelweg 11, 3012 Bern,
} 


\section{Abbreviations}

TiNOX titanium-nitride-oxide

DES drug-eluting stent(s)

PES paclitaxel-eluting stent(s)

SES sirolimus-eluting stent(s)

MACE major adverse cardiac event

MI myocardial infarction

TLR target lesion revascularisation

TVR target vessel revascularisation

$\mathrm{PCI}$ percutaneous coronary intervention

\section{Introduction}

Passive stent coating with titanium-nitride-oxide (TiNOX) has been shown to reduce platelet adhesion and fibrinogen binding in vitro and to reduce neointimal hyperplasia in the porcine restenosis model $^{1}$. In a randomised clinical trial, the TiNOX trial, TiNOX was found superior in terms of late lumen loss and restenosis, with fewer target lesion revascularisations (TLR) compared with stainless steel stents of otherwise identical design ${ }^{2}$. The beneficial effects of TiNOX stents were attributed to its high corrosion resistance and excellent biocompatibility. In vitro and in vivo studies showed rapid vascular healing without signs of inflammatory reactions and granuloma formation ${ }^{3,4}$. Furthermore, TiNOX stents were found to have NO-molecules on the coating surface ${ }^{5}$, which appear to have antiproliferative and antiaggregatory properties. In a long-term follow-up of the TiNOX trial, there was a $59 \%$ relative risk reduction of major adverse cardiac events (MACE) at 3-years compared with stainless steel stents $(95 \%$ CI $4 \%$ to $82 \%)^{6}$. A recent randomised trial comparing TiNOX with a zotarolimus-eluting stent, a newer generation drug-eluting stent, suggested that TiNOX was inferior in terms of angiographic late loss and binary restenosis ${ }^{7}$. The only available long-term clinical comparison of TiNOX stents with drug-eluting stents, a recently published observational study with propensity score adjustment, found a robust $52 \%$ relative risk reduction of MACE at 3-years as compared with PES $(95 \% \text { CI } 17 \text { to } 72 \%)^{8}$. We performed propensity-matched analyses nested in a registry to explore whether TiNOX stents are indeed superior to PES or to sirolimus-eluting stents (SES) in routine clinical practice at three years.

\section{Methods \\ PATIENTS}

All patients undergoing implantation of coronary stents at Bern University Hospital, Switzerland are entered into a dedicated registry. Between May 2004 (after completion of SIRTAX study) and February 2005, 542 consecutive patients underwent treatment with at least one SES (Cypher ${ }^{\mathrm{TM}}$; Cordis, Miami Lakes, FL, USA) and 507 consecutive patients underwent treatment with at least one PES (Taxus ${ }^{\mathrm{TM}}$, Boston Scientific Corporation, Natick, MA, USA). Between July 2005 and April 2007, 558 consecutive patients underwent treatment with TiNOX stents (Titan 2 Cross Max ${ }^{\mathrm{TM}}$; Hexacath, Paris, France). The 3-year follow-up was performed between February and June 2008 in patients who underwent implantation of SES or PES and between September 2009 and February 2010 in patients with TiNOX stents.
Eligible patients had a history of stable angina or acute coronary syndrome and presented with at least one lesion with a diameter stenosis $>50 \%$ in a vessel with a reference vessel diameter (RVD) between $2.25 \mathrm{~mm}$ and $4.00 \mathrm{~mm}$ suitable for stent implantation. Acute coronary syndrome included unstable angina according to Braunwald's definition, non-ST-elevation myocardial infarction and ST-elevation myocardial infarction. There were no limitations on the number of treated lesions and vessels, or lesion length. Exclusion criteria were a known allergy to acetylsalicylic acid, thienopyridines, heparin, stainless steel, titanium-nitride-oxide, sirolimus, paclitaxel, or contrast agents, previous implantation of another DES, and patients with terminal illness. The study complied with the Declaration of Helsinki regarding investigation in humans and was approved by the institutional ethics committee of Bern, Switzerland. All patients provided written informed consent.

TiNOX stents were available in diameters of 2.25 to $4.0 \mathrm{~mm}$ and in lengths of 8 to $28 \mathrm{~mm}$; SES were available in diameters of 2.25 to $3.5 \mathrm{~mm}$ and in lengths of 8 to $33 \mathrm{~mm}$; PES were available in diameters of 2.25 to $3.5 \mathrm{~mm}$ and in lengths of 8 to $32 \mathrm{~mm}$. Only patients who received a single type of study stent during the index procedure were eligible. Balloon angioplasty and stent implantation were performed according to standard techniques. Direct stenting was permitted. Full lesion coverage was attempted by implantation of one or multiple stents. Before, or at the time of the procedure, all patients were treated with at least $100 \mathrm{mg}$ acetylsalicylic acid, a $300 \mathrm{mg}$ loading dose of clopidogrel and unfractionated heparin in a dose of $5000 \mathrm{U}$ or $70-100 \mathrm{U} / \mathrm{kg}$. Glycoprotein IIb/IIIa antagonists were used at the discretion of the operator. A 12-lead electrocardiogram was obtained after the procedure prior to discharge. Creatine kinase (CK), $\mathrm{CK}-\mathrm{MB}$, and troponin I were assessed at least once after the procedure and repeated in case of laboratory abnormalities. All patients were discharged on acetylsalicylic acid $100 \mathrm{mg}$ daily indefinitely and clopidogrel $75 \mathrm{mg}$ daily for an intended duration of at least one month in stable and nine months in ACS patients in the TiNOX group and at least 12 months in the SES or PES group. However, the duration of dual antiplatelet therapy was at the discretion of the intervening physicians and may be lower than nine months in some of the ACS patients receiving a TiNOX stent depending on the individual appraisal of the bleeding risk and the classification of the ACS (unstable versus non-ST-elevation MI versus ST-elevation MI).

\section{STUDY ENDPOINTS AND DEFINITIONS}

The primary outcome was MACE as the composite of death overall, myocardial infarction (MI) or target vessel revascularisation (TVR). Secondary outcomes were death overall, TVR, TLR, MI and definite stent thrombosis. A target lesion revascularisation was defined as a repeated revascularisation (percutaneous or surgical) based on a stenosis within the stent or within the $5 \mathrm{~mm}$ borders proximal or distal to the stent. The diagnosis of MI was established whenever new Q-waves of at least 0.4 seconds duration in at least two contiguous leads appeared on the electrocardiogram with an elevated creatine kinase MB fraction level, or in the absence of pathologic Q-waves, an elevation in creatine kinase levels to more 
than twice the upper limit of normal and an elevated creatine kinase MB or troponin I level. Definite stent thrombosis was defined according to the definitions provided by the Academic Research Consortium $^{9}$. Repeat angiography was only clinically driven by symptoms or signs suggestive of myocardial ischaemia, since patients were not encouraged for routine repeat angiograms. All clinical events were adjudicated by two independent cardiologists blinded for the stent type. In case of disagreement, a third cardiologist was consulted for the final decision.

Baseline characteristics were defined as follows: patients were defined as diabetics whenever oral antidiabetic or insulin treatment was prescribed on a regular basis prior to the index hospitalisation. Renal failure was defined as creatinine serum level of $>150 \mu \mathrm{mol} / 1$. Smoking was defined as current smoking (at least six cigarettes per day). Bleeding disorder was defined as patients with a history of a clinically relevant gastrointestinal, urogenital or intracranial haemorrhage. Alcoholism was defined as chronic consumption of more than $30 \mathrm{~g}$ per day for men and more than $20 \mathrm{~g}$ per day for women.

\section{STATISTICAL ANALYSIS}

These were two propensity-matched superiority analyses. Sample size considerations were based on the recently published long-term follow-up of an observational study comparing TiNOX stents with PES, which found an approximate relative risk reduction for the composite of cardiac death, MI, or TVR of 50\% in favour of TiNOX stents at an event rate of $24 \%$ in the PES group at three years ${ }^{8}$. In the absence of additional clinical evidence, we assumed the same relative risk reduction for our pre-specified primary endpoint of MACE, defined as the composite of death overall, MI, or TVR, in TiNOX stents compared with either of the two types of DES (PES or SES). A sample size of 320 matched pairs would provide greater than $90 \%$ power to detect a relative risk of 0.50 in favour of TiNOX stents over PES or SES at a two-sided $\alpha$ of 0.025 after Bonferroni correction. Assuming that two-thirds of patients treated with TiNOX stents could be matched to patients treated with any of the two drug-eluting stents, approximately 500 patients in each group were necessary for the present analysis.

Baseline characteristics before and after matching are reported as means and standard deviations for continuous and absolute numbers and percentages for categorical variables. Baseline characteristics between the TINOX, SES, and PES patients were compared using an unpaired t-test and one-way analysis of variance as appropriate for comparisons of continuous variables between two and three groups, and a chi-square test for categorical variables. Then, we used propensity-score matching to account for differences in baseline characteristics between groups. The propensity scores for receiving TiNOX stents rather than SES or PES were estimated using a logit model with age, gender, and the following covariates associated at $\mathrm{p}<0.1$ in a multivariable model as independent variables: diabetes, smoking, acute coronary syndrome (ACS), low left ventricular ejection fraction of $<50 \%$, multivessel disease, small vessel disease (diameter $\leq 2.75 \mathrm{~mm}$ ), bleeding disorder, planned staged surgery within the next six months, and obligation to use Coumadin.
In order to assure comparable groups, the assumption of common support was applied, which indicates that patients with the same propensity score have a non-zero probability of receiving either TiNOX or one of the drug-eluting stents ${ }^{10}$. We estimated the Epanechnikov kernel probability densities of the propensity scores of the TiNOX and the drug-eluting stent groups based on propensity score increments of 0.04 . Observations with a propensity score $>0.5$ were then dropped, since the probability density of the propensity score of the TiNOX group definitely dropped below a pre-specified cut-off value of 0.4 at this point. Then, we performed a 1:1 nearest-neighbour calliper matching in a range of \pm 0.05 on the propensity score without replacement. The pool of patients who underwent implantation of a TiNOX stent was used twice, once for the comparison with SES and once for the comparison with PES. For each pair, we ensured equal follow-up times by discarding observation time in patients treated with SES or PES extending beyond the follow-up duration of corresponding patients receiving TiNOX stents and vice versa. We used Cox proportional hazards models that accounted for the 1:1 matching to calculate hazard ratios of all primary and secondary outcomes comparing TiNOX with SES and TiNOX with PES over the entire follow-up time of up to three years (primary time-point), and up to 30 days. In a sensitivity analysis, we additionally adjusted for all procedural characteristics and discharge medications. All p-values and 95\% confidence intervals are two-sided. All analyses were done in Stata version 11 (StataCorp LP, College Station, TX, USA).

\section{Results}

A total of 558 consecutive patients underwent PCI of at least one lesion with TiNOX coated stents (total 882 stents), 542 patients with SES (916 stents), and 507 patients with PES (891 stents). Table 1 presents a comparison of patients before propensity score matching. Patients with TiNOX stents were older, had more often diabetes, a low left ventricular ejection fraction (EF), bleeding disorder, staged surgery within the next six months and an obligation to use Coumadin, had less often small vessel disease and were less frequently smoking compared with patients treated with SES or PES. The three groups were similar in terms of gender, hypertension, renal impairment, acute coronary syndrome, multivessel disease and alcoholism. Out of 1,607 patients, 1,521 (95\%) completed planned follow-up up to three years: 523 patients receiving TiNOX stents (95\%), 508 patients receiving SES (94\%), and 481 patients treated with PES (95\%).

Of patients treated with TiNOX stents, 319 could be matched with 319 patients treated with SES, and 337 patients treated with TiNOX stents could be matched with 337 patients treated with PES. Table 2 shows baseline characteristics after matching. All baseline variables were well balanced in both matched datasets (TiNOX vs. SES and TiNOX vs. PES). Table 3 presents a comparison of procedural characteristics and discharge medication between stent types after matching. In general, procedural characteristics suggested a higher complexity in patients treated with drug-eluting stents, who had more stents implanted, a higher total stent length, smaller 
Table 1. Baseline characteristics before propensity score matching.

\begin{tabular}{|c|c|c|c|c|}
\hline & TNNOX & SES & PES & \multirow{2}{*}{$p$-value } \\
\hline Total & 558 & 542 & 507 & \\
\hline Age, years (mean $\pm S D$ ) & $66.5 \pm 12.0$ & $63.2 \pm 11.7$ & $65.3 \pm 11.4$ & $<0.001$ \\
\hline Male sex (n [\%]) & $432(77.4)$ & $429(79.2)$ & $371(73.2)$ & 0.06 \\
\hline Diabetes (n [\%]) & $134(24.0)$ & $91(16.8)$ & $89(17.6)$ & 0.004 \\
\hline Hypertension (n [\%]) & $299(53.6)$ & $275(50.7)$ & $268(52.9)$ & 0.62 \\
\hline Renal impairment (n [\%]) & $31(5.6)$ & $19(3.5)$ & $15(3.0)$ & 0.07 \\
\hline Smoking (n [\%]) & $258(46.2)$ & $300(55.4)$ & $257(50.7)$ & 0.01 \\
\hline Stable angina pectoris (n [\%]) & $247(44.3)$ & $266(49.1)$ & $237(46.8)$ & 0.28 \\
\hline $\begin{array}{l}\text { Acute coronary syndrome (n } \\
{[\%] \text { ) }}\end{array}$ & $311(55.7)$ & $276(50.9)$ & $270(53.3)$ & 0.28 \\
\hline ST-elevation MI (n [\%]) & $173(31.0)$ & $152(28.2)$ & $145(28.6)$ & 0.54 \\
\hline $\begin{array}{l}\text { Low left ventricular EF }(<50 \%) \\
\text { (n [\%]) }\end{array}$ & $214(38.4)$ & $142(26.2)$ & $126(24.9)$ & $<0.001$ \\
\hline Multivessel disease (n [\%]) & $368(66.0)$ & $355(65.5)$ & $338(66.7)$ & 0.92 \\
\hline Small vessel disease ( $[\%]$ ) & $185(33.2)$ & $250(46.1)$ & $202(39.8)$ & $<0.001$ \\
\hline Alcoholism (n [\%]) & $12(2.2)$ & $9(1.7)$ & $8(1.6)$ & 0.75 \\
\hline Bleeding disorder (n [\%]) & $10(1.8)$ & $1(0.2)$ & $0(0)$ & $<0.001$ \\
\hline $\begin{array}{l}\text { Staged surgery within next } \\
6 \text { months ( }[\%])\end{array}$ & $87(15.6)$ & $9(1.7)$ & $11(2.2)$ & $<0.001$ \\
\hline $\begin{array}{l}\text { Obligation to use Coumadin } \\
\text { (n [\%]) }\end{array}$ & $135(24.2)$ & $43(7.9)$ & $40(7.9)$ & $<0.001$ \\
\hline
\end{tabular}

Values are expressed in $n(\%)$ or mean $\pm S D$. Two-sided $p$-values were calculated using a chi-square test for categorical variables and a one way analysis of variance for continuous variables. EF: ejection fraction stent diameters, more saphenous vein graft interventions and a higher use of glycoprotein IIb/IIIa antagonists. Medical co-interventions, including beta blockers, ACE inhibitors and statins, were more frequent in patients who underwent implantation of a TiNOX stent. Median length of clopidogrel prescription was three months in patients treated with TiNOX (mean: 6.7 months, range: 0-36 months) and 12 months in patients treated with SES or PES (mean: 11.0 months, range: 0-36 months).

Table 4 presents all clinical outcomes for the matched groups (TiNOX vs. SES and TiNOX vs. PES) up to 30 days and up to three years. Kaplan-Meier curves are shown in Figure 1. The primary outcome MACE - the composite of death overall, MI, and TVRoccurred in $20 \%$ of patients with TiNOX stents, $19 \%$ of patients with SES, and $23 \%$ of patients with PES up to three years (Figure 1, panel A). The hazard ratio (HR) was 1.00 comparing TiNOX stents with SES (95\% CI 0.69-1.45, $\mathrm{p}=1.00)$, and 0.95 comparing TiNOX stents with PES (95\% CI 0.66-1.36, $\mathrm{p}=0.78$ ) (Table 4). A sensitivity analysis of the primary outcome up to three years adjusted for all procedural characteristics and discharge medications yielded similar results (TiNOX vs. SES: HR 1.08, 95\% CI 0.62-1.89, p=0.79; TiNOX vs. PES: HR 1.26, 95\% CI 0.76-2.07, $\mathrm{p}=0.37$ ).

Rates of death, TLR, and TVR were similar between groups, with hazard ratios around 1 and confidence intervals compatible with both, substantial advantages or disadvantages of the TiNOX stent over the drug-eluting stents (Table 4 and Figure 1, panels B, D and E). MI and stent thrombosis tended to be less frequent in patients treated with TiNOX stents as compared with SES or PES, with hazard ratios between 0.33 and 0.63 (Table 4), but confidence intervals were wide and overlapped the null effect at $1(\mathrm{p} \geq 0.18)$.

Table 2. Baseline characteristics after propensity score matching.

\begin{tabular}{|c|c|c|c|c|c|c|}
\hline & TINOX & SES & \multirow{2}{*}{$p$-value } & TINOX & PES & \multirow{2}{*}{$p$-value } \\
\hline Total & 319 & 319 & & 337 & 337 & \\
\hline Age, years (mean $\pm S D)$ & $63.8 \pm 12.0$ & $64.3 \pm 12.0$ & 0.65 & $64.1 \pm 12.0$ & $64.7 \pm 11.8$ & 0.53 \\
\hline Male sex (n [\%]) & $247(77.4)$ & 255 (79.9) & 0.44 & $262(77.7)$ & $257(76.3)$ & 0.65 \\
\hline Diabetes (n [\%]) & $54(16.9)$ & $53(16.6)$ & 0.92 & $62(18.4)$ & 66 (19.6) & 0.69 \\
\hline Hypertension (n [\%]) & $165(51.7)$ & $166(52.0)$ & 0.94 & $171(50.7)$ & $168(49.9)$ & 0.82 \\
\hline Renal impairment (n [\%]) & $14(4.4)$ & $13(4.1)$ & 0.84 & $14(4.2)$ & $12(3.6)$ & 0.69 \\
\hline Smoking (n [\%]) & $157(49.2)$ & $172(53.9)$ & 0.24 & $165(49.0)$ & $167(49.6)$ & 0.88 \\
\hline Stable angina pectoris ( $\mathrm{n}[\%]$ ) & $141(44.2)$ & $149(46.7)$ & 0.53 & $143(42.4)$ & $133(39.5)$ & 0.43 \\
\hline Acute coronary syndrome (n [\%]) & $178(55.8)$ & $170(53.3)$ & 0.53 & $194(57.6)$ & $204(60.5)$ & 0.43 \\
\hline ST-elevation MI (n [\%]) & $102(32.0)$ & $98(30.8)$ & 0.75 & $113(33.5)$ & 109 (32.3) & 0.74 \\
\hline Low left ventricular EF (<50\%) (n [\%]) & $98(30.7)$ & $97(30.4)$ & 0.93 & $105(31.2)$ & $102(30.3)$ & 0.80 \\
\hline Multivessel disease (n [\%]) & $206(64.6)$ & $206(64.6)$ & 1.00 & $217(64.4)$ & $219(65.0)$ & 0.87 \\
\hline Small vessel disease (n [\%]) & $116(36.4)$ & 109 (34.2) & 0.56 & $120(35.6)$ & 109 (32.3) & 0.37 \\
\hline Alcoholism (n [\%]) & $6(1.9)$ & $3(0.9)$ & 0.31 & $6(1.8)$ & $5(1.5)$ & 0.76 \\
\hline Bleeding disorder ( $\mathrm{n}[\%]$ ) & $0(0)$ & $0(0)$ & 1.00 & $0(0)$ & $0(0)$ & 1.00 \\
\hline Staged surgery within next 6 months (n [\%]) & $0(0)$ & $0(0)$ & 1.00 & $0(0)$ & $0(0)$ & 1.00 \\
\hline Obligation to use Coumadin ( $\mathrm{n}[\%]$ ) & $5(1.6)$ & $10(3.1)$ & 0.19 & $9(2.7)$ & $12(3.6)$ & 0.51 \\
\hline
\end{tabular}


Table 3. Procedural and discharge characteristics after propensity score matching.

\begin{tabular}{|c|c|c|c|c|c|c|}
\hline & TINOX & SES & \multirow{2}{*}{$p$-value } & TINOX & PES & \multirow{2}{*}{$p$-value } \\
\hline Total & 319 & 319 & & 337 & 337 & \\
\hline \multicolumn{7}{|l|}{ Procedural characteristics } \\
\hline Number of stents implanted (mean \pm SD) & $1.52 \pm 0.82$ & $1.72 \pm 0.89$ & 0.002 & $1.51 \pm 0.81$ & $1.73 \pm 0.95$ & 0.001 \\
\hline Average stent diameter (mean \pm SD) & $3.09 \pm 0.52$ & $2.93 \pm 0.33$ & $<0.001$ & $3.09 \pm 0.52$ & $2.96 \pm 0.34$ & $<0.001$ \\
\hline Total stent length (mean $\pm S D$ ) & $25.3 \pm 15.7$ & $32.5 \pm 18.7$ & $<0.001$ & $25.4 \pm 15.6$ & $30.2 \pm 17.1$ & $<0.001$ \\
\hline Multivessel stenting ( $\mathrm{n}[\%]$ ) & $48(15.1)$ & $60(18.8)$ & 0.21 & $52(15.4)$ & $58(17.2)$ & 0.53 \\
\hline Saphenous vein graft intervention (n [\%]) & $1(0.3)$ & $10(3.1)$ & 0.006 & $1(0.3)$ & $8(2.4)$ & 0.02 \\
\hline Glycoprotein IIb/IIla antagonists (n [\%]) & $50(15.7)$ & $101(31.7)$ & $<0.001$ & $54(16.2)$ & $113(33.5)$ & $<0.001$ \\
\hline \multicolumn{7}{|l|}{ Discharge medication } \\
\hline Acetylsalicylic acid (n [\%]) & $311(97.5)$ & $307(96.2)$ & 0.83 & $329(97.6)$ & $329(97.6)$ & 1.00 \\
\hline Clopidogrel (n [\%]) & $318(99.7)$ & $308(96.6)$ & 0.004 & $336(99.7)$ & $334(99.1)$ & 0.32 \\
\hline Oral anticoagulation (n [\%]) & $7(2.2)$ & $3(0.9)$ & 0.20 & $11(3.3)$ & $3(0.9)$ & 0.03 \\
\hline Beta blocker (n [\%]) & $264(82.8)$ & $168(52.7)$ & $<0.001$ & $281(83.4)$ & $207(61.4)$ & $<0.001$ \\
\hline ACE inhibitor (n [\%]) & $229(71.8)$ & $174(54.6)$ & $<0.001$ & $246(73.0)$ & $180(53.4)$ & $<0.001$ \\
\hline Statin (n [\%]) & $290(90.9)$ & $269(84.3)$ & 0.01 & $304(90.2)$ & $292(86.7)$ & 0.15 \\
\hline
\end{tabular}

Values are expressed in $\mathrm{n}(\%)$ or mean $\pm \mathrm{SD}$. Two-sided $p$-values were calculated using a chi-square test for categorical variables and an unpaired $t$-test for continuous variables. ACE inhibitor denotes angiotensin-converting enzyme inhibitor.

Table 4. Clinical outcome in the propensity-score-matched groups.

\begin{tabular}{|c|c|c|c|c|c|c|c|c|}
\hline & TINOX & SES & \multirow{2}{*}{$\begin{array}{c}\text { Hazard ratio } \\
(95 \% \mathrm{Cl})\end{array}$} & \multirow{2}{*}{ p-value } & TINOX & PES & \multirow{2}{*}{$\begin{array}{l}\text { Hazard ratio } \\
(95 \% \mathrm{CI})\end{array}$} & \multirow{2}{*}{$p$-value } \\
\hline Total & 319 & 319 & & & 337 & 337 & & \\
\hline \multicolumn{9}{|l|}{ Events up to 30 days (n [\%]) } \\
\hline MACE (death, MI, or TVR) & $13(4.1)$ & $11(3.5)$ & $1.09(0.48-2.47)$ & 0.84 & $13(3.9)$ & $14(4.2)$ & $0.86(0.40-1.85)$ & 0.70 \\
\hline Death overall & $7(2.2)$ & $6(1.9)$ & $1.17(0.39-3.47)$ & 0.78 & $7(2.1)$ & $9(2.7)$ & $0.78(0.29-2.09)$ & 0.62 \\
\hline Myocardial infarction & $1(0.3)$ & $5(1.6)$ & $0.20(0.02-1.71)$ & $0.22 *$ & $1(0.3)$ & $3(0.9)$ & $0.33(0.03-3.20)$ & $0.62^{*}$ \\
\hline TLR & $2(0.6)$ & $0(0)$ & $5.0(0.24-103.7)$ & $0.50 *$ & $2(0.6)$ & $4(1.2)$ & $0.50(0.09-2.73)$ & $0.69 *$ \\
\hline TVR & $5(1.6)$ & $0(0)$ & $11.0(0.61-198.1)$ & $0.06^{*}$ & $5(1.5)$ & $5(1.5)$ & $1.00(0.29-3.45)$ & $1.00 *$ \\
\hline Stent thrombosis & $1(0.3)$ & $0(0)$ & $3.0(0.12-73.4)$ & $1.00^{*}$ & $1(0.3)$ & $4(1.2)$ & $0.25(0.03-2.24)$ & $0.37 *$ \\
\hline \multicolumn{9}{|l|}{ Events up to 3 -years (n [\%]) } \\
\hline MACE (death, MI, or TVR) & $64(20.1)$ & $62(19.4)$ & $1.00(0.69-1.45)$ & 1.00 & $67(19.9)$ & $76(22.6)$ & $0.95(0.66-1.36)$ & 0.78 \\
\hline Death overall & $27(8.5)$ & $26(8.2)$ & $1.04(0.60-1.80)$ & 0.89 & $28(8.3)$ & $33(9.8)$ & $0.93(0.54-1.58)$ & 0.79 \\
\hline Myocardial infarction & $9(2.8)$ & $14(4.4)$ & $0.57(0.24-1.36)$ & 0.21 & $10(3.0)$ & $16(4.8)$ & $0.63(0.28-1.38)$ & 0.24 \\
\hline TLR & $24(7.5)$ & $22(6.9)$ & $1.05(0.58-1.88)$ & 0.88 & $25(7.4)$ & $26(7.7)$ & $1.00(0.57-1.76)$ & 1.00 \\
\hline TVR & $33(10.3)$ & $33(10.3)$ & $1.03(0.63-1.71)$ & 0.90 & $34(10.1)$ & $43(12.8)$ & $0.82(0.51-1.31)$ & 0.41 \\
\hline Stent thrombosis & $2(0.6)$ & $6(1.9)$ & $0.33(0.07-1.65)$ & 0.18 & $2(0.6)$ & $5(1.5)$ & $0.40(0.08-2.06)$ & 0.27 \\
\hline
\end{tabular}

\section{Discussion}

In these propensity-matched analyses, long-term clinical outcomes after implantation of TiNOX-coated stents and first generation drug-eluting stents (SES or PES) were similar for the three stent types. Hazard ratios for MACE, the composite primary outcome of death overall, myocardial infarction, or TVR were approximately one in both comparisons (TiNOX versus SES and TiNOX versus PES). There was a slight trend towards lower MI and stent thrombosis rates in patients treated with TiNOX stents compared to patients treated with SES or PES, but confidence intervals were wide and differences non-significant.

Our study has several limitations. It was not a randomised comparison between TiNOX stents and SES or PES, and therefore the results may be biased. However, we used appropriate propensityscore matching to ensure comparability of groups. Differences in procedural characteristics and co-medications initiated after stent implantation were observed, but by definition cannot be accounted for in a propensity matched analysis since these variables were 

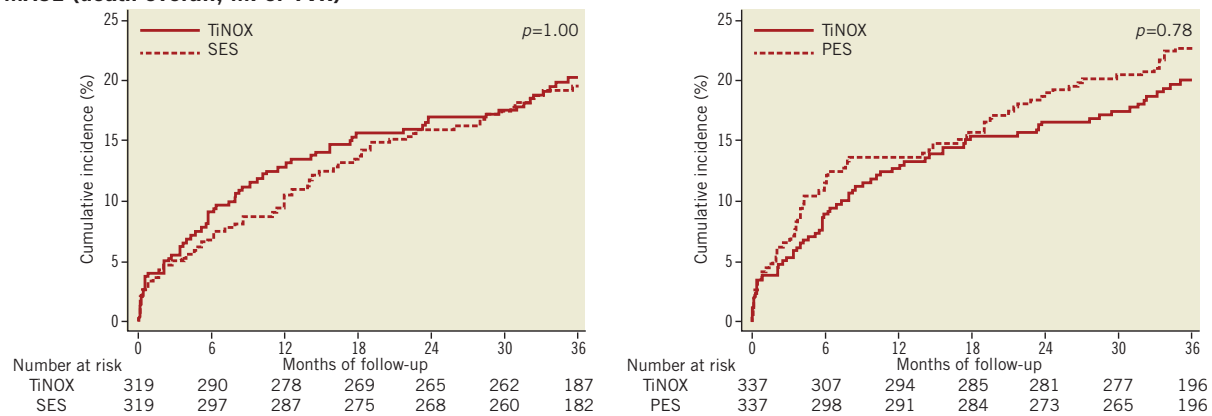

\section{B. Death overall}
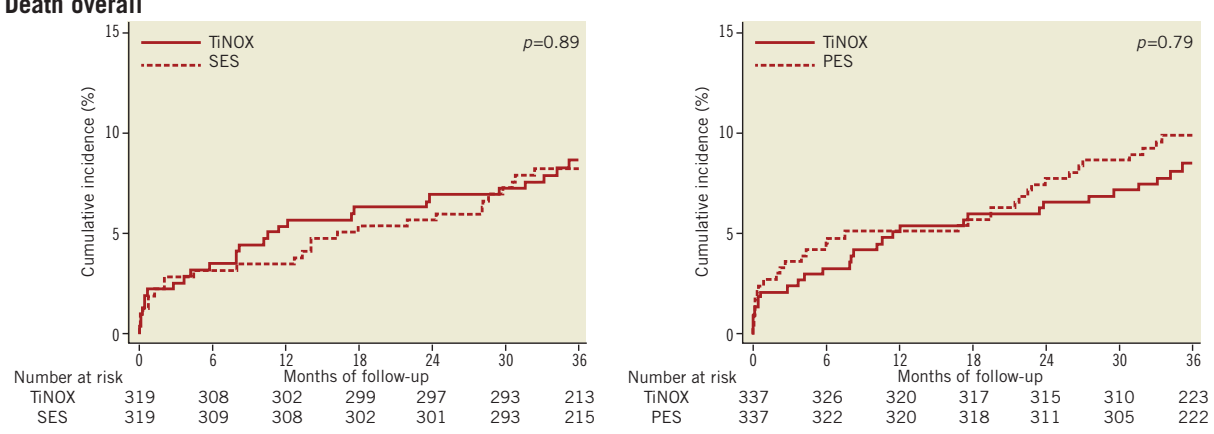

C. MI
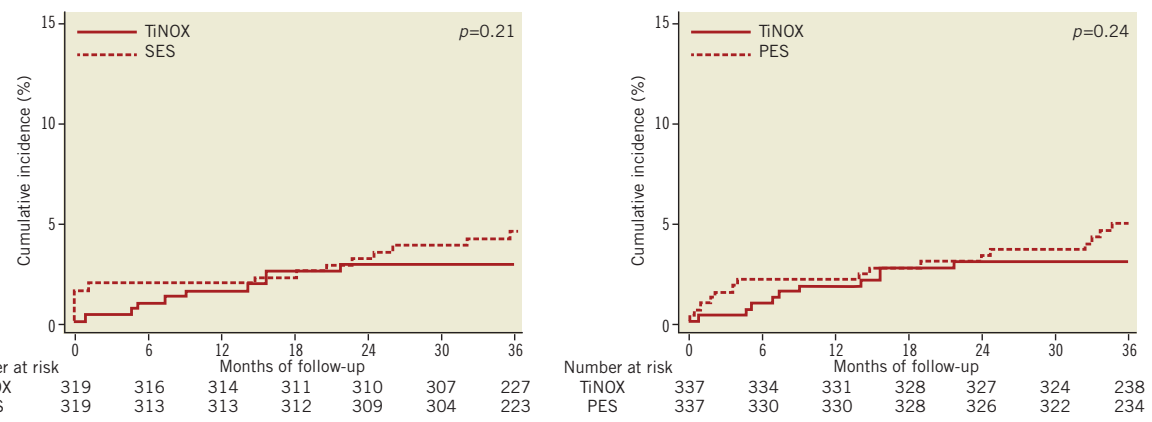

D. TLR
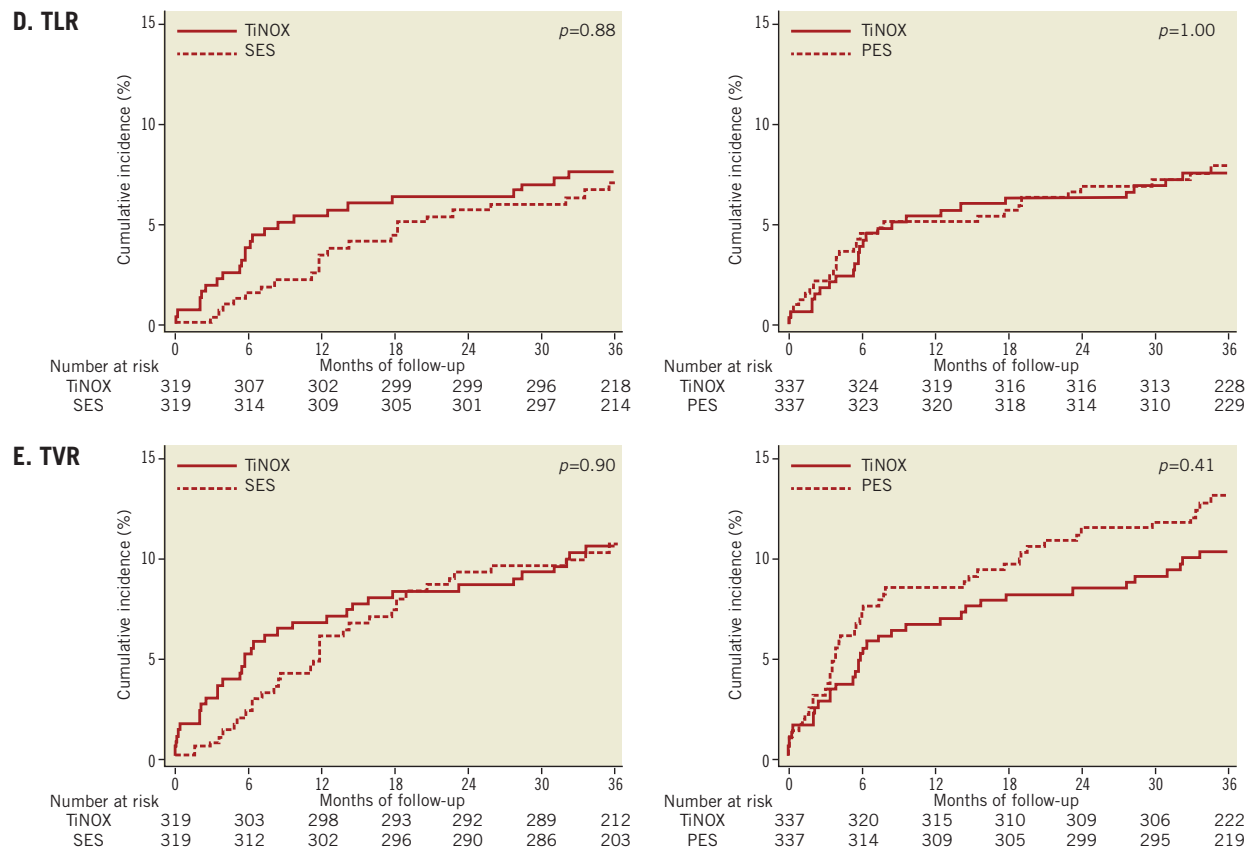

Figure 1. Clinical outcomes in the propensity-score matched groups. The Kaplan-Meier curves show the cumulative incidence of the primary outcome (panel A), overall death (panel B), myocardial infarction (MI, panel C), target lesion revascularisation (TLR, panel D) and target vessel revascularisation (TVR, panel E) for up to 3-years. The comparison between TiNOX and SES is shown on the left, the comparison between TiNOX and PES on the right. p-values were calculated using the two-sided Wald tests derived from Cox proportional hazards models. 
ascertained after treatment initiation and may be a reflection of the selected intervention ${ }^{11}$. The reason for the less frequent use of glycoprotein inhibitors in the TiNOX group is most likely related to a lower lesion complexity and to a higher proportion of TiNOX patients presenting with risk factors for bleeding or contraindications for glycoprotein inhibitors. To explain whether differences in procedural characteristics and co-medications could have influenced the observed outcomes, we performed a sensitivity analysis adjusted for these variables and found results to be robust, again with no evidence to suggest superiority of the TiNOX stent over drug-eluting stents. Another limitation is the sequential enrolment period. It cannot be excluded that changes in treatment may have had a favourable impact on clinical outcome although treatment protocols did not change during enrolment at our institution. The durations of dual antiplatelet therapy with acetylsalicylic acid and clopidogrel were different between the three groups and could also have influenced the clinical outcomes. Patients treated with TiNOX stents had a median duration of dual antiplatelet therapy of three months as compared to 12 months observed for patients treated with drug-eluting stents. If a shorter duration of dual antiplatelet therapy in patients treated with TiNOX stents had a clinical effect, this would have resulted in more clinical events in patients receiving the TiNOX stent after termination of dual antiplatelet therapy. This would have put the TiNOX stent at a disadvantage in our study. A clear strength of this study is that we included unselected, consecutive patients. This notion is supported by the fact that one third of all included patients underwent primary PCI for ST-elevation MI (Tables 1 and 2). The findings may therefore be representative for patients encountered in routine clinical practice. Since there was no protocol-mandated angiographic follow-up, observed MACE rates are likely to reflect clinical decision making and management pathways at our centre.

Mechanisms of action are completely different between drugeluting and TiNOX-coated stents. In the first group the coating of the stent blocks cell regeneration in the G1 cycle, preventing proliferation of smooth muscle cells and reducing restenosis within the stent. As a result, vascular healing is delayed and prevents ingrowth of stent struts partially or completely ${ }^{12-14}$. This lack of ingrowth and re-endothelialisation may be responsible for late and very late stent thrombosis ${ }^{15}$. In contrast, titanium-coated stents show rapid vascular healing within weeks or months. This has been attributed to the high corrosion resistance of the coating resulting in a high tissue compatibility with limited response to vessel injury. Platelet aggregation and fibrinogen binding has been shown to be reduced, resulting in a decreased rate of stent thrombosis and reduced neointimal growth ${ }^{1}$. Furthermore, the use of titanium nitride-oxide coating improves elasticity of the metal, minimising the risk of surface damages of the coating (cracks and splits of the coating). In addition, the titanium nitride-oxide forms nitric-oxide (NO) on the surface of the stent, which further reduces platelet aggregation and neointimal formation ${ }^{5}$. Considered together, titanium nitride-oxide coated stents show a favourable metal-tissue interaction with a comparable antipro- liferative behaviour to the drug-eluting stents, but not at the expense of reduced vascular healing.

In a recently published propensity score adjusted analysis, Karjalainen et al found treatment with TiNOX stents to result in better long-term outcomes than PES. After three years of follow-up, the risk of MACE defined as the composite of cardiac death, MI, or TVR was 52\% lower with TiNOX stents (adjusted HR 0.48, 95\%CI $0.28-0.83)^{8}$. The registry-based nature of our study meant that we had to adhere to an alternate definition of MACE as the composite of death overall, MI or TVR. Since the overall death rate in patients with coronary artery disease is typically driven by cardiac deaths, we assumed a similar relative risk reduction for both definitions, Karjalainen's ${ }^{8}$ and ours. However, we failed to reproduce their findings, and found our results (HR of MACE 0.95, 95\%-CI 0.66-1.36) hardly compatible. In our view, methodological differences are the most likely explanation for the difference in results. In our analysis, we were careful in measuring a wide range of pretreatment variables that might confound comparisons of TiNOX with drug-eluting stents. In addition, we addressed the assumption of common support, which indicates that patients with the same propensity score must have a non-zero probability of receiving either TiNOX or one of the drug-eluting stents ${ }^{10}$. If probability densities are too low in one of the groups, there is insufficient overlap of propensity scores and the assumption of common support is unlikely to be satisfied, and residual, unmeasured confounding may occur. Moreover, we used propensity score matching rather than conventional adjustment to further minimise confounding. Alternate explanations include the difference in endpoint definitions mentioned above and chance. Our results are compatible with shortterm results of randomised comparisons of TiNOX stents with PES in patients with acute myocardial infarction (the TITAX-AMI trial) ${ }^{16}$, and with a newer generation zotarolimus-eluting stent in patients with stable or unstable angina or non-ST-elevation $\mathrm{MI}^{7}$. In neither trial there was statistical evidence for a superiority of TiNOX stents over drug-eluting stents at 1-year: the RR of MACE versus PES was 0.78 in favour of TiNOX stents (95\% CI 0.43 to $1.43)^{16}$, the HR of MACE versus zotarolimus-eluting stents was 1.19 in favour of zotarolimus-eluting stents ( $95 \%$ CI 0.71 to 2.00$)^{7}$. Conversely, the 2-year follow-up of the TITAX-AMI trial suggested a lower rate of MACE in the TiNOX stent group compared with the PES group (HR $0.45,95 \%$ CI 0.26 to $0.77, \mathrm{p}=0.004$ ), which is somewhat at odds with our results ${ }^{17}$.

In conclusion, we did not find evidence to suggest a superiority of TiNOX stents over SES or PES at three years. Clinical outcomes were similar across stent types, even though most confidence intervals were wide and compatible with both, substantial advantages and disadvantages of TiNOX stents over SES or PES. The duration of dual antiplatelet therapy in patients who underwent implantation of a drug-eluting stent is established at six months or more ${ }^{18,19}$. In view of the reduced duration of dual antiplatelet therapy possibly required for the TiNOX stent, we suggest that TiNOX stents may be an alternative to drug-eluting stents, particularly in patients with relative or absolute contraindications to prolonged dual antiplatelet therapy. 


\section{Conflict of interest statement}

B. Meier has received educational and research support as well as consulting and lecture fees from Cordis and Boston Scientific. O. Hess has received travel grants from Boehringer-Ingelheim, Novartis, Servier and Hexacath. The other authors have not declared a conflict of interest.

\section{References}

1. Windecker S, Mayer I, De Pasquale G, Maier W, Dirsch O, De Groot P, Wu YP, Noll G, Leskosek B, Meier B, Hess OM. Stent coating with titanium-nitride-oxide for reduction of neointimal hyperplasia. Circulation 2001;104:928-33.

2. Windecker S, Simon R, Lins M, Klauss V, Eberli FR, Roffi M, Pedrazzini G, Moccetti T, Wenaweser P, Togni M, Tuller D, Zbinden R, Seiler C, Mehilli J, Kastrati A, Meier B, Hess OM. Randomized comparison of a titanium-nitride-oxide-coated stent with a stainless steel stent for coronary revascularization: the TiNOX trial. Circulation 2005;111:2617-22.

3. Steinemann SG. Metal implants and surface reactions. Injury 1996;27 Suppl 3:SC16-22.

4. Steinemann S, Mäusli A, Schröder A. Adhesion of bone to titanium. In: Christel P MA, Lee A, eds, ed Biological and Biomechanical Performance of Biomaterials Amsterdam, Netherlands: Elsevier; 1986;409-414.

5. Windecker S, Billinger M, Hess OM. Stent coating with titanium-nitride-oxide for prevention of restenosis. EuroIntervention 2006;2:146-8.

6. Moschovitis A, Simon R, Seidenstucker A, Klauss V, Baylacher M, Luscher TF, Moccetti T, Windecker S, Meier B, Hess OM. Randomised comparison of titanium-nitride-oxide coated stents with bare metal stents: five year follow-up of the TiNOX trial. EuroIntervention 2010;6:63-8.

7. Pilgrim T, Räber L, Limacher $A$, Löffel L, Wenaweser $P$, Cook S, Stauffer JC, Togni M, Vogel R, Garachemani A, Moschovitis A, Khattab AA, Seiler C, Meier B, Jüni P, Windecker S. Comparison of Titanium-Nitride-Oxide Coated Stents With ZotarolimusEluting Stents For Coronary Revascularisation: A Randomised Controlled Trial. JACC Cardiovasc Interv. 2011;4:672-82.

8. Karjalainen PP, Annala AP, Ylitalo A, Vahlberg T, Airaksinen KE. Long-term clinical outcome with titanium-nitrideoxide-coated stents and paclitaxel-eluting stents for coronary revascularization in an unselected population. Int J Cardiol 2010;144: 42-6.

9. Cutlip DE, Windecker S, Mehran R, Boam A, Cohen DJ, van Es GA, Steg PG, Morel MA, Mauri L, Vranckx P, McFadden E, Lansky A, Hamon M, Krucoff MW, Serruys PW. Clinical end points in coronary stent trials: a case for standardized definitions. Circulation 2007;115:2344-51.

10. Heckman J, Lalonde R, Smith J. The economics and econometrics of active labour market programs. In A Ashenfelter and D Card, eds, Handbook of Labour Economics, vol 3, Amsterdam: Elsevier Science 1999.
11. Heinze G, Juni P. An overview of the objectives of and the approaches to propensity score analyses. Eur Heart J. 2011;32: 1704-8.

12. Joner M, Finn AV, Farb A, Mont EK, Kolodgie FD, Ladich E, Kutys R, Skorija K, Gold HK, Virmani R. Pathology of drug-eluting stents in humans: delayed healing and late thrombotic risk. $J \mathrm{Am}$ Coll Cardiol 2006;48:193-202.

13. Nakazawa G, Finn AV, Joner M, Ladich E, Kutys R, Mont EK, Gold HK, Burke AP, Kolodgie FD, Virmani R. Delayed arterial healing and increased late stent thrombosis at culprit sites after drug-eluting stent placement for acute myocardial infarction patients: an autopsy study. Circulation 2008;118:1138-45.

14. Virmani R, Kolodgie FD, Farb A. Drug-eluting stents: are they really safe? Am Heart Hosp J 2004;2:85-8.

15. Yeh HI, Lu SK, Tian TY, Hong RC, Lee WH, Tsai CH. Comparison of endothelial cells grown on different stent materials. J Biomed Mater Res A 2006;76:835-41.

16. Karjalainen PP, Ylitalo A, Niemela M, Kervinen K, Makikallio T, Pietili M, Sia J, Tuomainen P, Nyman K, Airaksinen KE. Titanium-nitride-oxide coated stents versus paclitaxel-eluting stents in acute myocardial infarction: a 12-months follow-up report from the TITAX AMI trial. EuroIntervention 2008;4:234-41.

17. Karjalainen PP, Ylitalo A, Niemela M, Kervinen K, Makikallio T, Pietila M, Sia J, Tuomainen P, Nyman K, Airaksinen KE. Two-year follow-up after percutaneous coronary intervention with titanium-nitride-oxide-coated stents versus paclitaxel-eluting stents in acute myocardial infarction. Ann Med 2009;41:599-607.

18. Daemen J, Simoons ML, Wijns W, Bagust A, Bos G, Bowen JM, Braunwald E, Camenzind E, Chevalier B, Dimario C, Fajadet J, Gitt A, Guagliumi G, Hillege HL, James S, Juni P, Kastrati A, Kloth S, Kristensen SD, Krucoff M, Legrand V, Pfisterer M, Rothman M, Serruys PW, Silber S, Steg PG, Tariah I, Wallentin L, Windecker SW, Aimonetti A, Allocco D, Baczynska A, Berenger M, Boam A, Calle JP, Campo G, Carlier S, de Schepper J, Di Bisceglie G, Dobbels H, Farb A, Ghislain JC, Hellbardt S, Ten Hoedt R, Isaia C, de Jong P, Klasen E, Lekehal M, Lenarz L, Ni Mhullain F, Nagai H, Patteet A, Paunovic D, Potgieter A, Purdy I, Raveau-Landon C, Ternstrom S, Van Wuytswinkel J, Waliszewski M. ESC Forum on Drug Eluting Stents European Heart House, Nice, 27-28 September 2007. Eur Heart J 2009;30: 152-61.

19. Stettler C, Allemann S, Wandel S, Kastrati A, Morice MC, Schomig A, Pfisterer ME, Stone GW, Leon MB, de Lezo JS, Goy JJ, Park SJ, Sabate M, Suttorp MJ, Kelbaek H, Spaulding C, Menichelli M, Vermeersch P, Dirksen MT, Cervinka P, De Carlo M, Erglis A, Chechi T, Ortolani P, Schalij MJ, Diem P, Meier B, Windecker S, Juni P. Drug eluting and bare metal stents in people with and without diabetes: collaborative network meta-analysis. BMJ 2008;337:a1331. 